\title{
Genetic Perturbation of Redox Status and Fructose-Supported Elevation of Dark Anaerobic Hydrogen Evolution in Synechocystis sp. Strain PCC 6803
}

\author{
Adipa Chongsuksantikul ${ }^{1}$, Kazuhiro Asami ${ }^{1}$, Shiro Yoshikawa ${ }^{1}$ \& Kazuhisa Ohtaguchi ${ }^{1}$ \\ ${ }^{1}$ Tokyo Institute of Technology, Japan \\ Correspondence: Adipa Chongsuksantikul, Tokyo Institute of Technology, Japan. E-mail: adipa.c.aa@m.titech.ac.jp
}

Received: November 11, 2014 Accepted: November 18, 2014 Online Published: January 20, 2015

doi:10.5539/ijb.v7n2p19 URL: http://dx.doi.org/10.5539/ijb.v7n2p19

\begin{abstract}
The effects of fructose on the dark anaerobic hydrogen production of the genetically modified mutants from glucose tolerant derivative of unicellular cyanobacterium Synechocystis sp. strain PCC 6803 (GT strain) in nitrate-free buffer solution has been studied by following the time courses of the amounts of hydrogen, fructose, dry cell weight, lactate and acetate per culture volume and the amount of endogenous glucose per dry cell weight. Considering that hydrogen production on bidirectional NiFe-hydrogenase competes NAD(P)H with lactate dehydrogenase and alcohol dehydrogenase, mutants which lack lactate dehydrogenase ( $\Delta$ ddh mutant) and both lactate dehydrogenase and alcohol dehydrogenase ( $\Delta \mathrm{adh} \Delta \mathrm{ddh}$ mutant), were utilized. These genetic modifications have a high potential to redirect electrons to NiFe-hydrogenase for hydrogen generation. A supply of additive to increase electron supply has found to be a successful method to activate hydrogen production. Fructose was selected as an additive due to our previous observation that hydrogen production in GT strain was highly increased in the presence of $50 \mu \mathrm{mol} \mathrm{mL}{ }^{-1}$ fructose. Initial hydrogen production rate of $\Delta \mathrm{adh} \Delta \mathrm{ddh}$ mutant in the presence of $50 \mu \mathrm{mol} \mathrm{mL} \mathrm{m}^{-1}$ fructose was increased to $0.129 \mu \mathrm{mol} \mathrm{mL}^{-1} \mathrm{~h}^{-1}$ that was 5.11 times that of GT strain. This increase was associated with the initial increase in glucose accumulation rate. Hydrogen production by $\Delta \mathrm{adh} \Delta \mathrm{ddh}$ mutant in the presence of $50 \mu \mathrm{mol} \mathrm{mL} \mathrm{m}^{-1}$ fructose was quite stable for at least $120 \mathrm{~h}$. Fructose-mediated hydrogen production resulted in an 11-fold increase in the moles of hydrogen per culture volume at $120 \mathrm{~h}$ over controls.
\end{abstract}

Keywords: fructose, hydrogen, lactate dehydrogenase, alcohol dehydrogenase, NiFe-hydrogenase, nitrate-free, Synecocystis sp. strain PCC6803

\section{Introduction}

Establishment of sustainable and low emission fuels is an urgent issue due to the inevitable deprivation of petroleum resource and rising carbon dioxide emission. Cyanobacteria have attracted much attention as a biotechnical tool to convert carbon dioxide to clean fuel hydrogen because of the autotrophic growth to accumulate endogenous glucose with high growth rate, readily available genetic tools, low nutrient requirement, easiness to extract intracellular components and non-food competitor.

Synechocystis sp. strain PCC 6803 is the most studied unicellular and $\mathrm{N}_{2}$-non-fixing cyanobacterium with complete genetic database sequence (Kaneko et al., 1996). This stain is able to produce hydrogen on bidirectional NiFe-hydrogenase under dark anaerobic condition (Howarth \& Codd, 1985). The enzyme is annotated as NAD(P)H dependent in several works (Cournac et al., 2004; Germer et al., 2009) and ferredoxin/flavodoxin dependent in a recent work (Gutekunst et al., 2014). Dark anaerobic and nitrate-free metabolism generates $\mathrm{NAD}(\mathrm{P}) \mathrm{H}$ from the catabolism of high energy cellular components that are stored during photosynthesis. Catabolism of stored components is realized to maintain cell viability. This destructive metabolism results in the breakdown of complex biomaterials, the release of ATP and the evolution of many metabolites such as hydrogen, lactate and acetate.

Redox homeostasis is important for living systems. Reduction and oxidation in global cellular metabolisms are coupled to buffer the toxic effect of redox unbalance by gaining and losing electrons. Cellular energy metabolism is directed by $\mathrm{NADH}$ and $\mathrm{NAD}^{+}$, and biosynthetic pathways and antioxidant defense are regulated by their phosphorylated forms NADPH and $\mathrm{NADP}^{+}$. Redox homeostasis is regulated at the subcellular level, hence analysis of it in multicellular organism level presents a great deal of difficulties. Despite this fact, some studies 
have recently challenged the study on redox homeostasis utilizing computational analysis (Elvitigala et al., 2007) and experiments focusing on reactive oxygen species (ROS) and glutathione with unicellular cyanobacterium Synechocystis sp. strain PCC6803 (Guo et al., 2014; Cameron \& Pakrasi, 2010). Cyanobacterium is a photolithotroph that requires and captures radiant energy on thylakoid membrane utilizing water as electron donor and produces oxygen molecules, protons, electrons and subsequently NADPH and ATP. The generation of oxygen is crucial for discharging accumulated electrons. Above works have dealt with the harmful reactive oxygen species (ROS) The accumulated NADPH, protons and electrons are utilized in the Calvin cycle to buffer redox unbalance. Previous redox homeostasis studies on cyanobacteria have concerned with the biological status under the aerobic radiated condition, and there are remarkably few data available on redox homeostasis of cyanobacteria under anaerobic dark condition. Expression of NiFe-hydrogenase gene in Synechocystis sp. strain PCC 6803 has been proven to be essential for dark anaerobic mixotrophic growth on glucose (Gutekunst et al., 2014).

In our laboratory work, we have pursued several research works to characterize hydrogen production in Synechocystis sp. strain PCC6803. The amount of hydrogen produced from Synechocystis sp. strain PCC6803 is varied by how the cells have been prepared in photosynthesis prior to dark anaerobic fermentation. Compositions of ions for cell growth in photosynthesis highly affect hydrogen production in dark anaerobic condition (Yamamoto et al., 2012a). Dark anaerobic hydrogen production of GT strain was activated in the presence of some monosaccharide (Chongsuksantikul et al., 2014c). Cells of GT strain prepared in the photosynthesis medium with glucose and those dark incubated in the buffer solution with glucose yielded the higher amount of hydrogen per culture volume at the end of incubation (Yamamoto et al., 2012b). Glucose was utilized for cell growth. Among several monosaccharides, fructose has proven to greatly promote hydrogen production in GT strain. The limited heterotrophic growth of GT strain on fructose in buffer solution was observed (Chongsuksantikul et al., 2014b). To increase the supply of reductive compounds $\mathrm{NAD}(\mathrm{P}) \mathrm{H}$, the mutant lacking D-lactate dehydrogenase ( $\Delta$ ddh mutant) and that lacking both D-lactate dehydrogenase and alcohol dehydrogenase ( $\Delta \mathrm{adh} \Delta \mathrm{ddh}$ mutant) were constructed (Yamamoto et al., 2012c; Chongsuksantikul et al., 2014a). The initial rates of dark anaerobic hydrogen production in genetically modified mutants were increased from GT strain, while the amount of hydrogen per culture volume at $96 \mathrm{~h}$ of $\Delta \mathrm{ddh}$ mutant was comparable with that of GT strain and that of $\Delta \mathrm{adh} \Delta \mathrm{ddh}$ mutant was lower than that of GT strain and $\Delta$ ddh mutant. Redox homeostasis network appears to be changed by genetic modification of $\mathrm{NAD}(\mathrm{P}) \mathrm{H}$ related reactions. Those mutants represent a high hydrogen production potential, however, for increasing attainable level of the amount of hydrogen per culture volume, it is unavoidable to solve the problem of deactivation of NiFe-hydrogenase in mutants during dark incubation.

Thus the primary objective of this study was to stabilize long-term hydrogen production in genetically modified $\Delta \mathrm{ddh}$ mutant and $\Delta \mathrm{adh} \Delta \mathrm{ddh}$ mutant of glucose tolerant derivative of Synechocystis sp. strain PCC6803 utilizing fructose.

\subsection{Preliminary Remarks}

The glucose tolerant mutant of Synechocystis sp. strain PCC6803 generates molecular hydrogen by NiFe-hydrogenase, when cells aerobically and photosynthetically grown on BG-11 medium are incubated. The hydrogen production activity of anaerobic dark nitrate-free buffer solution is defined by

$$
a=\frac{r_{H 2}}{r_{H 2,0}}
$$

in which $r_{\mathrm{H} 2}\left(=\mathrm{d} y_{\mathrm{H} 2} / \mathrm{d} t\right)$ and $r_{\mathrm{H} 2,0}$ are rate of hydrogen production at time $t$ and that with a fresh inoculum. If first-order deactivation is assumed, the kinetic expression of Eq.(1) becomes

$$
r_{H 2}=\frac{d y_{H 2}}{d t}=r_{H 2,0} a=r_{H 2,0} \exp (-k t)
$$

in which $k$ is the deactivation constant. Integration of Eq.(2) results that

$$
y_{H 2}=\frac{r_{H 2,0}}{k}\{1-\exp (-k t)\}
$$

Previous studies have shown that the $y_{\mathrm{H} 2}$ estimated by Eq.(3) fits well with observed $y_{\mathrm{H} 2}$ (Chongsuksantikul et al. 2014c). Table 1 tabulates the model parameters $r_{\mathrm{H} 2,0}$ and $k$ that were reported in our previous works. Figure 1 shows the simulated time courses of $y_{\mathrm{H} 2}$ in GT strain (solid line), $\Delta \mathrm{ddh}$ mutant (broken line) and $\Delta \mathrm{adh} \Delta \mathrm{ddh}$ mutant (long dashed short dashed line) incubated in HEPES buffer solutions and in GT strain (solid line) incubated in HEPES buffer solution with $28 \mu \mathrm{mol} \mathrm{mL}^{-1}$ fructose. Initial hydrogen production rate of $\Delta \mathrm{ddh}$ mutant or $\Delta \mathrm{adh} \Delta \mathrm{ddh}$ 
mutant is higher than that of GT strain, while the attainable level of $y_{\mathrm{H} 2}\left(y_{\mathrm{H} 2, \mathrm{f}}\right)$ of $\Delta$ ddh mutant is comparable with that of GT strain and that of $\Delta \mathrm{adh} \Delta \mathrm{ddh}$ mutant is lower than that of GT strain or $\Delta \mathrm{ddh}$ mutant.

Table 1. Model parameters in Eq.(3) shown in previous reports of dark anaerobic hydrogen production by cells of GT strain, $\Delta$ ddh mutant and $\Delta \mathrm{adh} \Delta \mathrm{ddh}$ mutant of Synechocystis sp. strain PCC6803 in HEPES buffer solution without or with fructose. Cells were harvested at the late-logarithmic growth phase before dark anaerobic fermentation

\begin{tabular}{|c|c|c|c|c|c|c|c|}
\hline Strain & $\begin{array}{c}\text { Growth } \\
\text { phase of inoculum }\end{array}$ & Solution & $\begin{array}{c}X_{0} \\
{\left[\mathrm{mg} \mathrm{mL}^{-1}\right]}\end{array}$ & $\begin{array}{c}r_{\mathrm{H} 2,0} \\
{\left[\mu \mathrm{mol} \mathrm{mL} \mathrm{mL}^{-1} \mathrm{~h}^{-1}\right]}\end{array}$ & $\begin{array}{c}y_{\mathrm{H} 2, \mathrm{f}} \\
{\left[\mu \mathrm{mol} \mathrm{mL} \mathrm{mL}^{-1}\right]}\end{array}$ & $\begin{array}{c}K \\
{\left[\mathrm{~h}^{-1}\right]}\end{array}$ & Ref. \\
\hline \multirow{2}{*}{ GT strain } & \multirow{2}{*}{ Late-logarithmic } & $\mathrm{H}$ & 2.1 & 0.0309 & 2.18 & 0.0187 & Ref. 1 \\
\hline & & $\mathrm{H}+\mathrm{F}$ & 2.1 & 0.0467 & 3.05 & 0.0221 & Ref. 1 \\
\hline$\Delta$ ddh mutant & Late-logarithmic & \multirow{2}{*}{$\mathrm{H}$} & 2.1 & 0.0359 & 2.31 & 0.0213 & Ref. 2 \\
\hline$\Delta \mathrm{adh} \Delta \mathrm{ddh}$ mutant & Late-logarithmic & & 2.1 & 0.0355 & 1.48 & 0.0365 & Ref. 2 \\
\hline
\end{tabular}

$\overline{\Delta d d h}$ mutant, a derivative of GT strain that lacks lactate dehydrogenase activity; $\Delta$ adh $\Delta$ ddh mutant, a derivative of GT strain that lacks both lactate dehydrogenase activity and alcohol dehydrogenase activity; H, HEPES buffer solution; H+F, HEPES buffer solution with $28 \mu \mathrm{mol} \mathrm{mL} \mathrm{mL}^{-1}$ fructose; Ref1, Chongsuksantikul et al. 2014c; Ref2, Chongsuksantikul et al. 2014a;

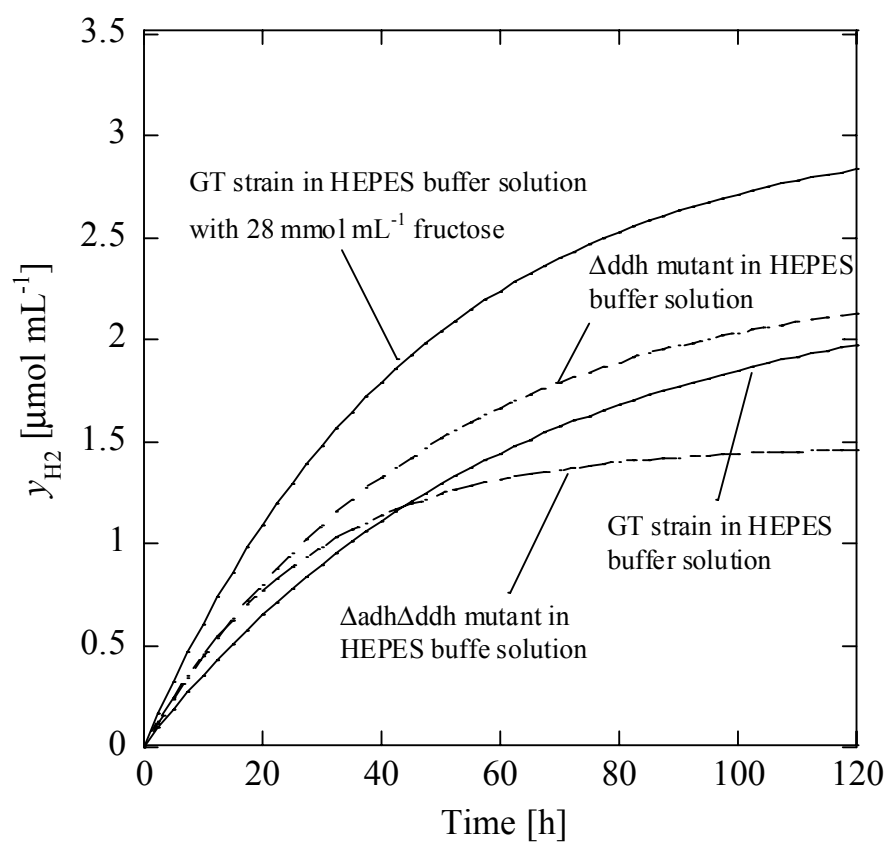

Figure 1. Estimated time courses of the number of moles of hydrogen per culture volume $\left(y_{\mathrm{H} 2}\right)$ for the dark anaerobic hydrogen production in GT strain (-), $\Delta$ ddh mutant (---) and $\Delta$ adh $\Delta$ ddh mutant (----) utilizing Eq.(3) and parameters in Table 1. Curves for GT strain are calculated utilizing parameters for runs with HEPES buffer solution without or with $28 \mu \mathrm{mol} \mathrm{mL}{ }^{-1}$ fructose. Curves for $\Delta$ ddh mutant and $\Delta \mathrm{adh} \Delta \mathrm{ddh}$ mutant are calculated utilizing parameters only for runs with HEPES buffer solution

\section{Materials and Methods}

\subsection{Strains}

The glucose tolerant mutant of Synechocystis sp. strain PCC6803 (GT strain) was kindly supplied by Prof. Hihara. The mutant of GT strain that lacks D-lactate dehydrogenase activity ( $\Delta$ ddh mutant) and both

D-lactate dehydrogenase and alcohol dehydrogenase activities ( $\Delta$ adh $\Delta$ ddh mutant) were previously constructed (Chongsuksantikul et al. 2014a). 


\subsection{Photoautotrophic Growth for Inoculum Preparation}

Cells of GT strain, $\Delta \mathrm{ddh}$ mutant and $\Delta \mathrm{adh} \Delta \mathrm{ddh}$ mutant of Synechocystis sp. strain PCC6803 were grown photoautotrophically on antibiotic-free BG-11 medium (initial $\mathrm{pH} 7.8$ ) that was aerated by $6 \%$ carbon dioxide in air in clear Pyrex glass test tube (TE-32, AGC TECHNO GLASS Co. Ltd.) at $34^{\circ} \mathrm{C}$ in water bath, surface of which was exposed to fluorescent lamps with a photosynthetic photon flux density (PPFD) of $100 \mu$ mol-photons $\mathrm{m}^{-2} \mathrm{~s}^{-1}$. Growth was monitored by measuring $\mathrm{OD}_{730}$ of cell suspension. One unit of $\mathrm{OD}_{730}$ represents the dry cell weight concentration $(X)$ of $0.369 \mathrm{mg} \mathrm{mL}^{-1}$. In preliminary experiments it was observed that cells were in logarithmic growth phase when $\mathrm{OD}_{730}$ of cell suspensions was 3 . Cultures of $\mathrm{OD}_{730}$ at 3 were centrifuged at $25^{\circ} \mathrm{C}, 3000 \mathrm{rpm}$ for $10 \mathrm{~min}$.

\subsection{Dark Anaerobic Incubation for Hydrogen Production}

The cell pellets were washed, re-suspended and incubated in $10 \mathrm{~mL}$ of $50 \mathrm{mmol} \mathrm{L} \mathrm{L}^{-1}$ HEPES (4-(2-hydroxyethyl)-1-piperazineethanesulfonic acid)) buffer (pH 7.8) in $32 \mathrm{~mL}$ glass test tube with butyl rubber cap. HEPES was selected for $\mathrm{pH}$ control preventing a drastic drop in $\mathrm{pH}$ during fermentation. The initial dry cell mass weight concentration was set at $2 \mathrm{mg} \mathrm{mL}^{-1}$ with $50 \mu \mathrm{mol} \mathrm{mL}{ }^{-1}$ fructose. Cell suspension was purged with nitrogen gas for a few minutes to remove oxygen gas. Incubation of cell suspension in test tube was carried out under dark anaerobic conditions, shaking at $145 \mathrm{rpm}$ in a reciprocating shaker. The reciprocating distance was 40 $\mathrm{mm}$ and the horizontal angle was about $30^{\circ} \mathrm{C}$. All experiments were carried out in duplicate.

The number of moles of hydrogen per culture volume $\left(y_{\mathrm{H} 2}\right)$ was determined by analyzing the composition of gas phase in $32 \mathrm{~mL}$ test tube utilizing gas chromatograph and thermal conductivity detector (GC-320, GL science Inc.; column, Molecular sieve 13X; carrier gas, nitrogen gas; column temperature, $37^{\circ} \mathrm{C}$; injector temperature, $45^{\circ} \mathrm{C}$; detector temperature $80{ }^{\circ} \mathrm{C}$ ).

The amount of cellular glycogen was estimated in terms of the number of moles of glucose equivalent. The number of moles of endogenous glucose per dry cell weight $\left(m_{\mathrm{G}}\right)$ was determined as follows: the amount of dry cell weight per culture volume was determined according to previous report (Yamamoto et al. 2012); cell pellets were collected by centrifugation at $25{ }^{\circ} \mathrm{C}, 3000 \mathrm{rpm}$ for $10 \mathrm{~min}$ then washed 3 times by deionized water to eliminate extracellular carbon sources; intracellular glycogen was extracted and decomposed to glucose in $50 \mu \mathrm{L}$ of $6 \mathrm{~N} \mathrm{HCl}$ at $80^{\circ} \mathrm{C}$ for 30 min; glucose amount was determined by using Glucose CII Test Wako (Wako Pure Chemical Ind., Ltd.).

Extracellular concentrations of lactate $\left(c_{\mathrm{L}}\right)$, acetate $\left(c_{\mathrm{A}}\right)$ and ethanol $\left(c_{\mathrm{E}}\right)$ in a $500 \mu \mathrm{L}$ portion of supernatants were analyzed by HPLC (JASCO PU-2080 Plus and UV-2075 Plus). Mobile phase was $18 \mathrm{mmol} \mathrm{L}^{-1} \mathrm{KH}_{2} \mathrm{PO}_{4}$, $\mathrm{pH}$ of which was adjusted at 2.3 with $\mathrm{H}_{3} \mathrm{PO}_{4}$. Flow rate of mobile phase was $0.7 \mathrm{~mL} \mathrm{~min}{ }^{-1}$. Column temperature was $30{ }^{\circ} \mathrm{C}$. A $10 \mu \mathrm{L}$ of supernatant sample was injected by using $10 \mu \mathrm{L}$ syringes. The wave length of $210 \mathrm{~nm}$ was used for detection of metabolites.

Unreacted fructose concentration was analyzed by HPLC (Shimadzu LC-10AD and RID-6A) with a $6.0 \times 150 \mathrm{~mm}$ column SZ5532 (Showa Denko Co.). Column temperature was set at $50^{\circ} \mathrm{C}$. Mobile phase was $70 \%$ acetonitrile with water. Mobile phase flow rate was set to be $0.7 \mathrm{~mL} / \mathrm{min}$. A $10 \mu \mathrm{L}$ of supernatant sample was injected by using a $10 \mu \mathrm{L}$ syringe.

\section{Results and Discussions}

Our previous works show that fructose largely elevates the dark anaerobic hydrogen production of GT strain cells from logarithmic growth phase and optimum fructose concentration regarding hydrogen production is $50 \mu \mathrm{mol}$ $\mathrm{mL}^{-1}$ (Chongsuksantikul et al., 2014b), and that, in the absence of fructose, the initial hydrogen production rate of $\Delta$ ddh mutant prepared form late-logarithmic growth phase in photosynthesis is higher than that of GT strain. Dark anaerobic incubation of those cells in the presence of glucose also shows that the rate of hydrogen production by $\Delta$ ddh mutant is higher than that of GT strain (Yamamoto et al., 2012c; Chongsuksantikul et al., 2014a). Therefore, a series of dark anaerobic hydrogen production experiments were performed in which cells of $\Delta \mathrm{ddh}$ mutant and $\Delta \mathrm{adh} \Delta \mathrm{ddh}$ mutant from logarithmic growth phase were incubated in HEPES buffer solution without or with $50 \mu \mathrm{mol} \mathrm{mL} \mathrm{m}^{-1}$ fructose.

In Figure 2, effects of fructose upon dark anaerobic hydrogen production in GT strain, $\Delta$ ddh mutant and $\Delta \mathrm{adh} \Delta \mathrm{ddh}$ mutant are shown. Cells were incubated in HEPES buffer solution or HEPES buffer solution with $50 \mu \mathrm{mol} \mathrm{mL}$ fructose. The amount of hydrogen produced from unit volume of solution $\left(y_{\mathrm{H} 2}\right)$, the amount of endogenous glucose in glycogen of a unit dry cell weight $\left(m_{\mathrm{G}}\right)$, dry cell weight per solution volume $(X)$, the concentrations of fructose, lactate and acetate were determined. 

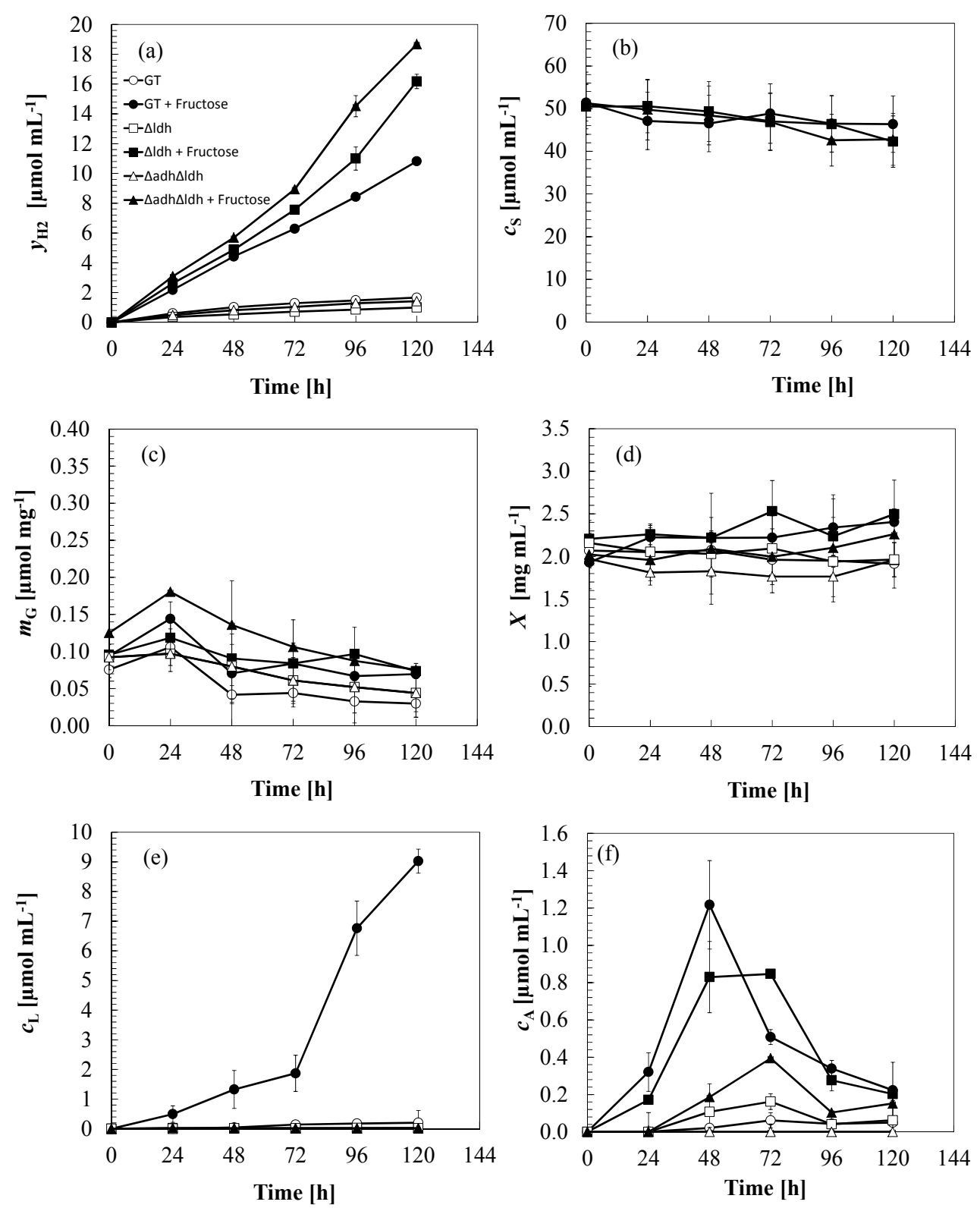

Figure 2. Time courses of culture parameters for dark anaerobic hydrogen production using GT strain cells $(\circ, \bullet)$, $\Delta$ ddh mutant cells $(\square, \boldsymbol{\bullet})$ and $\Delta$ adh $\Delta$ ddh mutant cells $(\Delta, \mathbf{\Lambda})$ in HEPES buffer solutions (shown by open symbols) and HEPES buffer solutions with $50 \mu \mathrm{mol} \mathrm{mL}^{-1}$ fructose (shown by solid symbols). (a) $y_{\mathrm{H} 2}$, number of moles hydrogen per culture volume, (b) $c_{\mathrm{S}}$, concentration of unreacted exogenous fructose, (c) $m_{\mathrm{G}}$, number of moles of endogenous glucose per dry cell weight, (d) $X$, concentration of dry cell weight, (e) $c_{\mathrm{L}}$, concentration of lactate and

(f) $c_{\mathrm{A}}$, concentration of acetate. Gas phase was nitrogen gas. All experiments were carried at least in duplicate

The curves of $y_{\mathrm{H} 2}$ versus time in Figure 2(a) show that fructose increased initial hydrogen production rate and stabilized and accelerated hydrogen production rate after the initial stage. The initial hydrogen production rates in GT strain, $\Delta$ ddh mutant and $\Delta \mathrm{adh} \Delta \mathrm{ddh}$ mutant, which were $0.025,0.015$ and $0.020 \mu \mathrm{mol} \mathrm{mL}^{-1} \mathrm{~h}^{-1}$, respectively, in the absence of fructose, were increased to $0.091,0.109$ and $0.129 \mu \mathrm{mol} \mathrm{mL}^{-1} \mathrm{~h}^{-1}$, respectively, in the presence of fructose. Fructose is found to largely enhance NiFe-hydrogenase activity. The hydrogen production rates after initial stage in GT strain, $\Delta$ ddh mutant and $\Delta \mathrm{adh} \Delta \mathrm{ddh}$ mutant were declined with time as shown by Eq.(3). The hydrogen production in GT strain in fructose shown in Figure 2(a) is related by

$$
r_{H 2}=r_{H 2,0}
$$


with the deactivation constant $k$ at $0 \mathrm{~h}^{-1}$. The rates of hydrogen production in $\Delta$ ddh mutant in fructose from $0 \mathrm{~h}$ to $84 \mathrm{~h}$ and in $\Delta \mathrm{adh} \Delta \mathrm{ddh}$ mutant in fructose from $0 \mathrm{~h}$ to $72 \mathrm{~h}$ are also related by Eq.(4). After that hydrogen production in $\Delta$ ddh mutant and $\Delta \mathrm{adh} \Delta \mathrm{ddh}$ mutant in fructose were accelerated. Details concerning fructose effect and dehydrogenase elimination effect on hydrogen production are not entirely clarified, however, presence of exogenous fructose or elimination of genes coding for $\mathrm{NAD}(\mathrm{P}) \mathrm{H}$ consuming dehydrogenases appears related to metabolic reactions that continuously generate and supply electrons and $\mathrm{NAD}(\mathrm{P}) \mathrm{H}$ to NiFe-hydrogenase. If $t_{\mathrm{C}}$ is the transition time from stable hydrogen production to accelerated hydrogen production, $t_{\mathrm{C}}$ values for $\Delta \mathrm{ddh}$ mutant and $\Delta \mathrm{adh} \Delta \mathrm{ddh}$ mutant are 84 and $72 \mathrm{~h}$, respectively. The $y_{\mathrm{H} 2}$ values at $120 \mathrm{~h}$ of runs with fructose for GT strain, $\Delta \mathrm{ddh}$ mutant and $\Delta \mathrm{adh} \Delta \mathrm{ddh}$ mutant were $10.8,16.2$ and $18.7 \mu \mathrm{mol} \mathrm{mL}^{-1}$, respectively. This numbers were very much improved from non-substrate fermentation conditions which yielded hydrogen gas as $1.66,1.00$ and 1.42 $\mu \mathrm{mol} \mathrm{mL} L^{-1}$ from GT, $\Delta$ ddh and $\Delta \mathrm{adh} \Delta \mathrm{ddh}$ strains, respectively.

In Figure 2(b), the affinity of derivatives from GT strain to fructose is extremely low when compared to that to glucose (data not shown). Fructose was consumed by cells of GT strain, $\Delta$ ddh mutant and $\Delta \mathrm{adh} \Delta \mathrm{ddh}$ mutant for maintaining cell mass stability. The consumption of fructose by GT, $\Delta$ ddh and $\Delta \mathrm{adh} \Delta \mathrm{ddh}$ strains were comparable. Consumption of fructose during $120 \mathrm{~h}$ was 5.1-8.4 $\mu \mathrm{mol} \mathrm{mL} \mathrm{L}^{-1}$. High hydrogen production of those cells in the presence of fructose was not likely resulted from direct fructose consumption.

In Figure 2(c), the time courses of the amount per culture volume of glycogen in terms of endogenous glucose $\left(m_{\mathrm{G}}\right)$ was displayed. In the first $24 \mathrm{~h}$ of dark incubation in HEPES buffer solution without or with fructose, the $m_{\mathrm{G}}$ increased in GT strain, $\Delta$ ddh mutant and $\Delta \mathrm{adh} \Delta \mathrm{ddh}$ mutant. This amount of endogenous glucose is corresponding to consumption of fructose. The peak value of $m_{\mathrm{G}}$ of runs with fructose is higher than that without fructose. The $\Delta \mathrm{adh} \Delta \mathrm{ddh}$ mutant converted more fructose to endogenous glucose than GT strain and $\Delta \mathrm{ddh}$ mutant. The glycogen content dropped during dark anaerobic fermentation. The highest drop in $m_{\mathrm{G}} X$ from $24 \mathrm{~h}$ to $120 \mathrm{~h}$ was $0.183 \mu \mathrm{mol}$ $\mathrm{mL}^{-1}$ that was observed in run with $\Delta \mathrm{adh} \Delta \mathrm{ddh}$ mutant in fructose solution. Hydrogen generated in this run is 25.5 times that estimated from the theoretical yield of $\mathrm{NAD}(\mathrm{P}) \mathrm{H}$ in glycolysis. Cells used fructose for gluconeogenesis in the first $24 \mathrm{~h}$ then for glycolysis from glycogen after $24 \mathrm{~h}$. At the end of fermentation, all strains had the same level of glycogen content.

In Figure 2(d), the time courses of the dry cell weight concentration of cyanobacterium cells $(X)$ was illustrated. The dry cell weight concentration of GT strain, $\Delta$ ddh mutant and $\Delta \mathrm{adh} \Delta \mathrm{ddh}$ mutant slowly decreased with time during $120 \mathrm{~h}$ in the absence of fructose. The aqueous solution for cell suspension was consisted of milliQ grade water and HEPES-KOH for $\mathrm{pH}$ buffering. Nitrate was totally removed from the system. The buffer solution is confirmed to be insufficient to support cell viability of GT strain, $\Delta$ ddh mutant and $\Delta$ adh $\Delta$ ddh mutant. In the presence of fructose, the $X$ of GT strain increased in the first $24 \mathrm{~h}$, was constant between $48 \mathrm{~h}$ and $72 \mathrm{~h}$ and increased again after $72 \mathrm{~h}$, the $X$ of $\Delta$ ddh mutant was constant in the first $48 \mathrm{~h}$, increased between $48 \mathrm{~h}$ and $72 \mathrm{~h}$, decreased between $72 \mathrm{~h}$ and $96 \mathrm{~h}$ and increased after $96 \mathrm{~h}$, and the $X$ of $\Delta \mathrm{adh} \Delta \mathrm{ddh}$ mutant was constant for the first $72 \mathrm{~h}$ and increased after $72 \mathrm{~h}$. The dry cell weight concentrations of GT strain, $\Delta$ ddh mutant and $\Delta$ adh $\Delta$ ddh mutant at $120 \mathrm{~h}$ were higher than the initial concentrations. Curves for runs with fructose in Figures 2 (c) and (d) show that GT strain, $\Delta$ ddh mutant and $\Delta \mathrm{adh} \Delta \mathrm{ddh}$ mutant are capable of limited heterotrophic growth on fructose in HEPES buffer solution. In the presence of fructose, the $X$ at $120 \mathrm{~h}$ was highest in runs with GT strain and $\Delta \mathrm{ddh}$ mutant and lowest that with $\Delta \mathrm{adh} \Delta \mathrm{ddh}$ mutant. It is observed that growth period of $\Delta \mathrm{ddh}$ mutant is later than that of GT strain, and that of $\Delta \mathrm{adh} \Delta \mathrm{dh}$ mutant is later than that of $\Delta \mathrm{ddh}$ mutant. Instability of dry cell weight concentration in dark anaerobic nitrate-free HEPES buffer solution was suppressed by fructose. This result shows that fructose supports cell viability in the dark anaerobic condition.

In Figure 2(e), the time courses of lactate concentration $\left(c_{\mathrm{L}}\right)$ are shown. The production of lactate by GT strain in the presence of fructose is extremely high. Lactate production of GT strain in the presence of fructose was activated at $72 \mathrm{~h}$. At $120 \mathrm{~h}$, lactate concentration of run with GT strain, which was $0.204 \mu \mathrm{mol} \mathrm{mL}^{-1}$ in buffer solution, increased to $9.02 \mu \mathrm{mol} \mathrm{mL}{ }^{-1}$ in the presence of fructose. Photosynthetic growth for cell preparation and dark anaerobic incubation were performed in the absence of antibiotics, hence the observation of trace amount lactate in runs with $\Delta \mathrm{ddh}$ mutant and $\Delta \mathrm{adh} \Delta \mathrm{ddh}$ mutant shows the drop of phenotype of lactate dehydrogenase deficiency.

In Figure 2 (f), the time courses of acetate concentration $\left(c_{\mathrm{A}}\right)$ were plotted. Acetate concentrations of runs with fructose were higher than those without fructose, and increased drastically during 48-72 $\mathrm{h}$. In the presence of fructose, acetate concentration was highest in GT strain, second highest in $\Delta$ ddh mutant and lowest in $\Delta \mathrm{adh} \Delta \mathrm{ddh}$ mutant. Acetate concentrations were highest during 48-72 $\mathrm{h}$ then the concentration dropped. The peaks of acetate concentration in runs with buffer solutions were $0.062,0.162$, and $0 \mu \mathrm{mol} \mathrm{mL}^{-1}$ for GT strain, $\Delta$ ddh mutant and $\Delta \mathrm{adh} \Delta \mathrm{ddh}$ mutant, respectively, and those with buffer solutions with fructose were $1.21,0.847$ and $0.394 \mu \mathrm{mol}$ 
$\mathrm{mL}^{-1}$ for them, respectively. The concentration of acetate after $72 \mathrm{~h}$ was extremely low. The consumption of acetate is highest in run with GT strain, second highest in run with $\Delta$ ddh mutant and lowest in run with $\Delta \mathrm{adh} \Delta \mathrm{ddh}$ mutant. This order is reverse of that of hydrogen production, while close to that of dry cell weight production. It suggests that acetate consumption after the peak seems related to late cell growth

Ethanol concentrations in runs without or with fructose were not in detachable level. Our previous report shows the ethanol production of GT strain, $\Delta$ ddh mutant and $\Delta$ adh $\Delta$ ddh mutant are $0.70,1.01$ and $0.47 \mu \mathrm{mol} \mathrm{mL}^{-1}$, respectively, in the presence of glucose after $96 \mathrm{~h}$ (Chongsuksantikul et al., 2014), hence fructose fermentation of above strains appears to be different from glucose fermentation.

High production of hydrogen, endogenous glucose and acetate were observed if fructose was present. This observation raised very interesting points concerning participation of fructose in $\mathrm{NAD}(\mathrm{P}) \mathrm{H}$ production or redirection of $\mathrm{NAD}(\mathrm{P}) \mathrm{H}$ in the dark. The slight higher fructose consumption by mutants could be the reason that mutants took long time for cell growth therefore cell kept utilizing more carbon source. However at $120 \mathrm{~h}$, difference of final dry cell weight concentrations among three strains was not large. Mutants consumed more fructose while produced less acid than GT strain. The $m_{\mathrm{G}}$ of Figure 2(c) is relatively stable in this period. More trials are required to find the products from acetate.

Cellular state variables of GT strain, $\Delta$ ddh mutant and $\Delta \mathrm{adh} \Delta \mathrm{ddh}$ mutant are summarized in Table 2, The initial hydrogen production rates of $\Delta \mathrm{ddh}$ mutant and $\Delta \mathrm{adh} \Delta \mathrm{ddh}$ mutant increased 3-fold to 7-fold over GT strain when fructose was present. Hydrogen production from mutant lacking both ddh and adh genes yielded extremely high amount of hydrogen.

Table 2. Fructose-mediated dark anaerobic hydrogen production of $\Delta$ ddh mutant and $\Delta$ adh $\Delta$ ddh mutant of Synechocystis sp. strain PCC6803. That of GT strain is also shown as a reference. $\Delta$ ddh, GT strain derivative lacking lactate dehydrogenase; $\Delta \mathrm{adh} \Delta \mathrm{ddh}$ mutant, GT strain derivative lacking both lactate dehydrogenase and alcohol dehydrogenase. Data of runs without or with $50 \mu \mathrm{mol} \mathrm{mL}^{-1}$ fructose were analyzed. The $y_{\mathrm{H} 2,1}$ was a number of moles of hydrogen per unit volume of buffer solution after $120 \mathrm{~h}$

\begin{tabular}{|c|c|c|c|c|c|c|}
\hline Strain & $\begin{array}{l}\text { Growth } \\
\text { phase of } \\
\text { inoculum }\end{array}$ & Solution & $\begin{array}{c}X_{0} \\
{\left[\mathrm{mg} \mathrm{mL}^{-1}\right]}\end{array}$ & $\frac{r_{\mathrm{H} 2,0}}{\left[\mu \mathrm{mol} \mathrm{mL} \mathrm{m}^{-1} \mathrm{~h}^{-1}\right]}$ & $\begin{array}{c}y_{\mathrm{H} 2,1} \\
{\left[\mu \mathrm{mol} \mathrm{mL}^{-1}\right]}\end{array}$ & $\begin{array}{c}K \\
{\left[\mathrm{~h}^{-1}\right]}\end{array}$ \\
\hline GT strain & Logarithmic & \multirow{3}{*}{$\begin{array}{l}\text { HEPES buffer } \\
\text { solution }\end{array}$} & 2.1 & 0.0252 & 1.66 & 0.0151 \\
\hline$\Delta$ ddh mutant & Logarithmic & & 2.2 & 0.0150 & 1.00 & 0.0115 \\
\hline $\begin{array}{c}\Delta \mathrm{adh} \Delta \mathrm{ddh} \\
\text { mutant }\end{array}$ & Logarithmic & & 2.0 & 0.0202 & 1.42 & 0.0119 \\
\hline GT strain & Logarithmic & \multirow{3}{*}{$\begin{array}{l}\text { HEPES buffer } \\
\text { solution with } \\
50 \mu \mathrm{mol} \mathrm{mL} \mathrm{m}^{-1} \\
\text { fructose }\end{array}$} & 1.9 & 0.0911 & 10.8 & 0 \\
\hline$\Delta$ ddh mutant & Logarithmic & & 2.2 & 0.109 & 16.2 & 0 \\
\hline $\begin{array}{c}\Delta \text { adh } \Delta \text { ddh } \\
\text { mutant }\end{array}$ & Logarithmic & & 2.0 & 0.129 & 18.7 & 0 \\
\hline
\end{tabular}

The amount per culture volume of hydrogen produced from GT strain was extremely high when logarithmic growth phase cells were incubated in dark anaerobic with supplement of fructose. This result implied that cells prepared from logarithmic growth phase have higher ability to utilize fructose.

Previously we reported that the deletion of the genes coding for competitive enzymes to hydrogenase was effective for increasing the initial hydrogen production rate of cells prepared from late-logarithmic growth phase. Present study shows that, if fructose is present, mutant cells prepared not from late-logarithmic growth phase but from logarithmic growth phase produce highest amount of hydrogen. The selection of growth phase affects hydrogen production in mutants greatly. The presence of fructose significantly activates hydrogen production from mutants.

The overview of the data shown in Figure 2 indicates that genetic perturbation of redox status that is brought by disruption of genes coding for lactate dehydrogenase and alcohol dehydrogenase plays an integral part to increase hydrogen production. Deletion of lactate dehydrogenase activity and alcohol dehydrogenase activity results not only redirection of $\mathrm{NAD}(\mathrm{P}) \mathrm{H}$ molecule for lactate dehydrogenase and alcohol dehydrogenase to NiFe-hydrogenase but also reforming the redox homeostasis networks. The increased amount of hydrogen is 
higher than that expected by above redirection of $\mathrm{NAD}(\mathrm{P}) \mathrm{H}$. Genetically modified mutants appear to represent a cellular state under the added load of mutation. Fructose plays the other integral part to increase hydrogen production. Dry cell weight concentration of mutants is supported by fructose as that of GT strain. In the presence of fructose, cells of GT strain, $\Delta \mathrm{ddh}$ mutant and $\Delta \mathrm{adh} \Delta \mathrm{ddh}$ mutant express the redox balance systems to constantly make-up NAD $(\mathrm{P}) \mathrm{H}$ molecules utilized by NiFe-hydrogenase. The supernumerary NAD $(\mathrm{P}) \mathrm{H}$ synthesis in mutants appear to trigger the second reformation of the redox balance systems during 48-76 h. This reformation contributes to further increase the amount of hydrogen per culture volume. The second reformation occurs when acetate production is changed to acetate assimilation.

Our work has showed that fructose is important for hydrogen production in GT strain, $\Delta$ ddh mutant and $\Delta \mathrm{adh} \Delta \mathrm{ddh}$ mutant. The low consumption of fructose suggests that the fructose-mediated hydrogen production is economical regarding fructose supply since the unreacted fructose after a batch hydrogen production can be utilized in a subsequent repeated-batch hydrogen production. Fructose is abundant in nature, hence the application of fructose to dark anaerobic hydrogen production of GT strain, $\Delta \mathrm{ddh}$ mutant and $\Delta \mathrm{adh} \Delta \mathrm{ddh}$ mutant in nitrate-free solution seems to be a good possibility.

Our observation that fructose supports cell concentration in the dark anaerobic nitrate-free condition is supported by a previous work that shows that fructose is a photoheterotrophic growth substrate of Anabaena (Ungerer et al. 2008). There are also previous reports that seem to contradict our findings. For phototrophic growth of Synechocystis sp. strain PCC 6803, fructose was reported to represent a toxicity (Flores \& Schmetterer, 1986). Photohetrotrophic growth of Synechocystis sp. strain PCC 6714 and some of other cyanobacteria on fructose have been reported to be hardly observed (Rippka et al., 1979; Joset et al., 1988). Cyanobacterium is a photosynthetic organism utilizing carbon dioxide for a main carbon source, there are remarkably few data available on the dark anaerobic heterotrophic growth. This work has opened the dark anaerobic heterotrophic growth of Synechocystis sp. strain PCC6803.

\section{Conclusion}

The hydrogen production of the glucose tolerant mutant of Synechococystis sp. strain PCC6803 in dark anaerobic HEPES buffer solution is found to be largely elevated by supply of fructose and elimination of dehydrogenase genes. Dark anaerobic $120 \mathrm{~h}$ incubation of a mutant lacking both lactate dehydrogenase genes and alcohol dehydrogenase genes in HEPES buffer solution with fructose is found to increase the amount of hydrogen per culture volume 11-fold over that without fructose. Fructose is observed to shift-up the amount of endogenous glucose per dry cell weight and to increase the stability of dry cell weight. The mechanism by which perturbation in redox status is related to under fructose remains to be elucidated. This work has proven that deletion of dehydrogenase enzyme results in the redirection of more electrons to flow to hydrogenase and the supplement of fructose contributes to long-term supply of electrons. Genetic perturbation in redox status and fructose addition in HEPES buffer solution, which we first elucidated in this study, appear to be a very promising biological approach to elevate dark anaerobic hydrogen production in cyanobacteria. This result has yielded very high number of moles of hydrogen per culture volume as no less than $18.7 \mu \mathrm{mol} \mathrm{mL}^{-1}$ when $2 \mathrm{mg} \mathrm{ml}^{-1}$ dry cell weight is utilized. This can be considered for future commercialization of biological process for hydrogen production by cyanobacteria.

\section{References}

Cameron, J. C., \& Pakrasi, H. B. (2010) Essential role of glutathione in acclimation to environmental and redox perturbations in the cyanobacterium Synechocystis sp. PCC 6803. Plant Physiology, 154(4), 1672-1685. http://dx.doi.org/10.1104/pp.110.162990

Chongsuksantikul, A., Asami, K., Yoshikawa, S., \& Ohtaguchi, K. (2014a). Dark Anaerobic Hydrogen Production in the Mutants of Synechocystis sp. Strain PCC6803-GT Defective in Lactate Dehydrogenase Activity and/or Alcohol Dehydrogenase Activity, Incubated in Buffer Solutions With or Without Glucose. International Journal of Biology, 7(1), 33. http://dx.doi.org/10.5539/ijb.v7n1p33

Chongsuksantikul, A., Asami, K., Yoshikawa, S., \& Ohtaguchi, K. (2014b). Fructose-Mediated Elevation of Hydrogen Production in Glucose Tolerant Mutant of Synechocystis Sp. Strain PCC 6803 under the Dark Anaerobic Nitrate-Free Condition. Journal of Bioprocessing \& Biotechniques, 4(6), http://dx.doi.org/10. 4172/2155-9821.1000175

Chongsuksantikul, A., Asami, K., Yoshikawa, S., \& Ohtaguchi, K. (2014c) Hydrogen production by anaerobic dark metabolism in Synechocystis sp. strain PCC6803-GT: effect of monosaccharide in nitrate free solution. Journal of Biochemical Technology, 5(3), 735-742 
Cournac, L., Guedeney, G., Peltier, G., \& Vignais, P. M. (2004). Sustained photoevolution of molecular hydrogen in a mutant of Synechocystis sp. strain PCC 6803 deficient in the type I NADPH-dehydrogenase complex. Journal of bacteriology, 186(6), 1737-1746. http://dx.doi.org/10.1128/JB.186.6.1737-1746.2003

Elvitigala, T., Singh, A. K., Khandelwal, A., Bhattacharya-Pakrasi, M., Aurora, R., Pakrasi, H. B., ... Ghosh, B. K. (2007). Computational Analysis of the Redox stress response in organisms. International Conference on Systems Biology.

Flores, E., \& Schmetterer, G. (1986). Interaction of fructose with the glucose permease of the cyanobacterium Synechocystis sp. strain PCC 6803. Journal of Bacteriology, 166(2), 693-696.

Germer, F., Zebger, I., Saggu, M., Lendzian, F., Schulz, R., \& Appel, J. (2009). Overexpression, isolation, and spectroscopic characterization of the bidirectional [NiFe] hydrogenase from Synechocystis sp. PCC 6803. Journal of Biological Chemistry, 284(52), 36462-36472. http://dx.doi.org/10.1074/jbc.M109.028795

Guo, J., Nguyen, A. Y., Dai, Z., Su, D., Gaffrey, M. J., Moore, R. J., ... Koppenaal, D. W. (2014). Proteome-wide Light/Dark Modulation of Thiol Oxidation in Cyanobacteria Revealed by Quantitative Site-Specific Redox Proteomics. Molecular \& Cellular Proteomics: mcp. M114, 041160. http://dx.doi.org/10.1074/mcp.M114. 041160

Gutekunst, K., Chen, X., Schreiber, K., Kaspar, U., Makam, S., \& Appel, J. (2014). The Bidirectional NiFe-hydrogenase in Synechocystis sp. PCC 6803 Is Reduced by Flavodoxin and Ferredoxin and Is Essential under Mixotrophic, Nitrate-limiting Conditions. Journal of Biological Chemistry, 289(4), 1930-1937. http://dx.doi.org/10.1074/jbc.M113.526376

Howarth, D C., \& Codd, G. A. (1985). The Uptake and Production of Molecular Hydrogen by Unicellular Cyanobacteria. Journal of General Microbiology, 131(7), 1561-1569. http://dx.doi.org/10.1099/00221287131-7-1561

Joset, F., Buchou, T., Zhang, C C., \& Jeanjean, R. (1988). Physiological and genetic analysis of the glucose-fructose permeation system in two Synechocystis species. Archives of Microbiology, 149(5), 417-421. http://dx.doi.org/10.1007/bf00425581

Kaneko, T., Sato, S., Kotani, H., Tanaka, A., Asamizu, E., Nakamura, Y., ... Tabata, S. (1996). Sequence Analysis of the Genome of the Unicellular Cyanobacterium Synechocystis sp. Strain PCC6803. II. Sequence Determination of the Entire Genome and Assignment of Potential Protein-coding Regions. DNA Research, 3(3), 109-136. http://dx.doi.org/10.1093/dnares/3.3.109

Rippka, R., Deruelles, J., Waterbury, J. B., Herdman, M., \& Stanier, R. Y. (1979). Generic assignments, strain histories and properties of pure cultures of cyanobacteria. Journal of General microbiology, 111(1), 1-61.

Ungerer, J. L., Pratte, B. S., \& Thiel, T. (2008). Regulation of Fructose Transport and Its Effect on Fructose Toxicity in Anabaena spp. Journal of bacteriology, 190(24), 8115-8125. http://dx.doi.org/10.1128/jb.00886 $-08$

Yamamoto, T., Asami, K., \& Ohtaguchi, K. (2012a). Anaerobic production of hydrogen in the dark by Synechocystis sp. strain PCC 6803: effect of photosynthesis media for cell preparation. Journal Biochemical Technology, 3(4), 344-348.

Yamamoto, T., Chongsuksantikul, A., Asami, K., \& Ohtaguchi, K. (2012b). Anaerobic Production of Hydrogen in the Dark by Synechocystis sp. strain PCC 6803 supplemented with D-glucose. Journal Biochemical Technology, 4(1), 464-468.

Yamamoto, T., Chongsuksantikul, A., Asami, K., \& Ohtaguchi, K. (2012c). Improvement of anaerobic production of hydrogen in the dark by genetic mutation strains of Synechocystis sp. strain PCC 6803. Journal Biochemical Technology, 4(2), 600-603.

\section{Copyrights}

Copyright for this article is retained by the author(s), with first publication rights granted to the journal.

This is an open-access article distributed under the terms and conditions of the Creative Commons Attribution license (http://creativecommons.org/licenses/by/3.0/). 